CLINICAL STUDY

\title{
Hepatic steatosis, GH deficiency and the effects of GH replacement: a Liverpool magnetic resonance spectroscopy study
}

Chris J Gardner, Andrew J Irwin, Christina Daousi, Ian A McFarlane, Franklin Joseph ${ }^{1}$, Jimmy D Bell ${ }^{3}$, E Louise Thomas ${ }^{3}$, Valerie L Adams ${ }^{2}$, Graham J Kemp ${ }^{2,4}$ and Daniel J Cuthbertson

Department of Obesity and Endocrinology, Clinical Sciences Centre, University of Liverpool, University Hospital Aintree, Longmoor Lane, Liverpool L9 7 AL, UK, ${ }^{1}$ Countess of Chester Hospital, Chester CH2 1UL, UK, ${ }^{2}$ MARIARC, University of Liverpool, Liverpool L69 3GE, UK, ${ }^{3}$ Metabolic and Molecular Imaging Group, Imperial College London, MRC Clinical Sciences Centre, London W12 OHS, UK and ${ }^{4}$ Department of Musculoskeletal Biology, University of Liverpool, Liverpool L69 3GA, UK

(Correspondence should be addressed to D J Cuthbertson; Email: daniel.cuthbertson@liverpool.ac.uk)

\begin{abstract}
Objective: Non-alcoholic fatty liver disease (NAFLD) is reported to be more common in patients with GH deficiency (GHD) than in the general population. We aimed to determine: i) liver fat in patients with GHD compared with age and body mass index (BMI)-matched controls; and ii) effect of 6 months of GH replacement (GHR) on liver fat.

Participants and methods: The study included 28 GHD patients and 24 controls. 12 patients were studied before and after 6 months of GHR. Anthropometry, liver enzymes and lipid profiles were measured, and body composition and intrahepatocellular lipid (IHCL) were determined by magnetic resonance imaging and spectroscopy.

Results: Age and BMI (median (inter-quartile range)) of patients and controls were 52.6 (14) vs 52.6 (12) years $(P=0.9)$ and $27.8(24.7,34.7)$ vs $27.9(25.1,32.1) \mathrm{kg} / \mathrm{m}^{2}(P=0.9)$. IGF1 was lower in the patients $(11.5$ vs $16.0 \mathrm{nmol} / \mathrm{l}, P=0.002)$. There was no difference in liver transaminases, lipids or IHCL between patients and controls $(2.8(1.3,8.6)$ vs $5.0(1.5,12.7), P=0.72)$, despite significantly higher visceral fat in GHD patients. Thirty-two percent of patients and $50 \%$ of controls had NAFLD (defined as IHCL $>5.6 \%$ ), and the relationship between IHCL and BMI was the same in each group. GHR significantly reduced abdominal subcutaneous and visceral fat in all patients; however, GHR did not reduce liver fat.

Conclusions: NAFLD is equally common in patients with GHD and matched controls. GHR is associated with a hierarchical reduction in fat deposition (fat loss: visceral $>$ subcutaneous $>$ liver). Further studies involving GHD patients with NAFLD are required to conclude the role of GHR in treating NAFLD.
\end{abstract}

European Journal of Endocrinology 166 993-1002

\section{Introduction}

Untreated GH deficiency (GHD) is associated with multiple features of the metabolic syndrome including insulin resistance, obesity, dyslipidaemia and hypertension $(1,2,3)$. Body composition analysis in GHD has shown increased central adiposity and visceral fat, and reductions in lean muscle mass, which have been linked to the metabolic syndrome $(4,5)$. Treatment with recombinant $\mathrm{GH}(\mathrm{rGH})$ has been shown to improve many of these features $(6,7,8,9)$.

Non-alcoholic fatty liver disease (NAFLD), as the hepatic manifestation of the metabolic syndrome, has similarities with adult GHD, being associated with insulin resistance and increased cardiovascular mortality (10). Patients with GHD tend to gain weight more rapidly and are on average more obese than controls $(11,12)$, so it could be argued that the increased prevalence of the metabolic syndrome in GHD is simply related to obesity. Against this, GHD is an independent predictor of NAFLD in patients with hypopituitarism (13). Furthermore, patients with hypopituitarism including GHD have increased prevalence of NAFLD compared with body mass index (BMI)matched patients with hypopituitarism and normal GH secretion (2). These data suggest that GHD may be an independent risk factor for the development of NAFLD. Previous studies in this area have been limited by reliance on less sensitive methodologies to detect NAFLD, such as abdominal ultrasonography. Studies have also suffered from poor matching of clinical characteristics, such as age and BMI, between the cases and controls. 
While rGH has been shown to produce clinically significant improvements in body composition, lipid profiles and insulin sensitivity, reports of improvement in NAFLD have been limited to isolated case reports (14, $15,16)$. Likewise, treatment with rGH has been shown to improve insulin sensitivity in obese patients without GHD $(17,18,19)$ and in patients with type 2 diabetes (20), but the effect on liver and muscle fat has not been documented. With proton magnetic resonance spectroscopy $\left({ }^{1} \mathrm{H}-\mathrm{MRS}\right)$, it is possible to non-invasively quantify triglyceride (TG) within liver (21) and skeletal muscle (22) (intrahepatocellular lipid (IHCL) and intramyocellular lipid (IMCL)). These measurements are metabolically and physiologically relevant as IHCL is a better predictor of metabolic risk than visceral fat in obese patients (23), and IMCL is also inversely associated with insulin sensitivity in sedentary patients (24). These measurements can easily be combined with whole-body magnetic resonance imaging (MRI) for volumetric analysis of total and regional subcutaneous and visceral fat.

Based on the previous reports of increased prevalence of NAFLD in patients with GHD, compared with controls matched for age, gender and BMI, we hypothesised that that the primary outcome measure of liver fat would be higher in GHD patients compared with controls. We anticipated that the altered phenotype might explain the clustering of cardiometabolic risk factors observed in this patient group. Consistent with this hypothesis, we further hypothesised that treatment with rGH for 6 months would be associated with reductions in IHCL and IMCL.

\section{Materials and methods}

The Liverpool research ethics committee approved the study. Written informed consent was obtained from all subjects before the study.

\section{Study design}

This was a cross-sectional study comparing long standing ( $>1$ year) untreated GHD patients with controls who were mean matched according to age and BMI; thus, we used two independent but comparable groups. Within this study a nested cohort of 12 patients commencing rGH were studied longitudinally before and 6 months after commencement of rGH. Specific restrictions apply to the initiation of rGH for patients with GHD in the UK, such that biochemical deficiency must be accompanied by a symptom score $>11 / 25$ using a validated questionnaire (assessment of GHD in adults) (25). Thus some GHD patients in the UK will never receive replacement therapy.

\section{Clinical and laboratory measurements}

Twenty-eight GHD patients attending the tertiary endocrine service at University Hospital Aintree, Liverpool, were recruited between April 2009 and February 2011. The time from the pituitary insult to study recruitment was a median of 5 years (range: 1-33 years). Baseline characteristics are shown in Table 1. Of the two patients with Cushing's disease, both were in long-term remission ( $>5$ years). Inclusion criteria included GH response $<3 \mu \mathrm{g} / \mathrm{l}$ after glucagon stimulation (26). Twenty-four controls were recruited by local advertisement. Exclusion criteria included alcohol intake $>21$ units/week for men and $>14$ units/week for women (20), drugs associated with steatosis, a history of viral hepatitis, autoimmune or metabolic liver disease (haemachromatosis, alpha-1 antitrypsin deficiency or Wilson's disease). In addition, controls were ineligible if they had a history of traumatic brain injury, subarachnoid haemorrhage or an intracranial intervention which may have hypopituitarism as a consequence. Controls were screened for GHD by clinical history and examination.

Of the eight women in the GH-deficient group, all except two were pre-menopausal, of which two women

Table 1 Original diagnoses, management and number of associated pituitary hormone deficits in 28 patients with GHD.

\begin{tabular}{|c|c|c|}
\hline $\begin{array}{l}\text { Patient } \\
\text { no. }\end{array}$ & Diagnosis & $\begin{array}{l}\text { No. of hormone } \\
\text { deficiencies in } \\
\text { addition to GHD }\end{array}$ \\
\hline 1 & Macroprolactinoma & 2 \\
\hline 2 & Idiopathic hypopituitarism & 2 \\
\hline 3 & Meningioma, craniotomy, DXT & 3 \\
\hline 4 & Mid-brain tumour, DXT & 0 \\
\hline 5 & Macroprolactinoma, DXT & 3 \\
\hline 6 & SAH & 0 \\
\hline 7 & Macroadenoma, TSS & 0 \\
\hline 8 & $\begin{array}{l}\text { Frontal oligoastrocytoma, } \\
\text { craniotomy, DXT }\end{array}$ & 1 \\
\hline 9 & SAH & 0 \\
\hline 10 & Cushing's, TSS & 0 \\
\hline 11 & Macroadenoma & 0 \\
\hline 12 & SAH & 0 \\
\hline 13 & TBI & 1 \\
\hline 14 & Macroadenoma & 0 \\
\hline 15 & Pineal germinoma, DXT & 1 \\
\hline 16 & Macroprolactinoma, DXT & 3 \\
\hline 17 & Macroadenoma, TSS, DXT & 3 \\
\hline 18 & Macroprolactinoma & 1 \\
\hline 19 & Macroadenoma, TSS & 0 \\
\hline 20 & Empty sella & 0 \\
\hline 21 & Pituitary apoplexy, TSS & 1 \\
\hline 22 & $\mathrm{SAH}$ & 0 \\
\hline 23 & Cushing's, TSS, DXT & 2 \\
\hline 24 & Suprasellar arachnoid cyst & 2 \\
\hline 25 & Pituitary apoplexy & 2 \\
\hline 26 & Intrasellar meningioma, craniotomy & 2 \\
\hline 27 & TSHoma, TSS, radioiodine & 0 \\
\hline 28 & Macroprolactinoma & 3 \\
\hline
\end{tabular}

SAH, subarachnoid haemorrhage; TBI, traumatic brain injury; DXT, radiotherapy; TSS, transsphenoidal surgery. 
were taking hormone replacement therapy. In the control group three women were post-menopausal. Seven patients and two controls were taking statins for hypercholesterolaemia, while seven patients in each group were on anti-hypertensive medications, none of which would be expected to affect liver fat. One patient in the GH-deficient group was taking metformin for type 2 diabetes and remained on the same dose. Two patients in the GHD group were taking anti-convulsants. Six patients with GHD were also taking hydrocortisone replacement. Following an overnight fast, patients had blood drawn for insulin-like growth factor 1 (IGF1), total cholesterol, HDL, LDL, TGs, glucose, alanine aminotransferase (ALT), aspartate aminotransferase (AST) and gamma-glutamyltranspeptidase (GGT), which were measured using standardised assays.

Serum GH and IGF1 levels were analysed in the hospital laboratory using chemiluminescent immunometric assays using IMMULITE 2000 (Siemens Medical Solutions Diagnostics, Erlangen, Germany) according to the manufacturer's instructions.

Weight was measured to the nearest $0.1 \mathrm{~kg}$ wearing light clothing on TANITA scales (Tanita BC420; Dolby Medical, Stirling, UK) and height measured to the nearest $0.5 \mathrm{~cm}$.

\section{MR methods}

Participants underwent MRI scanning in a $1.5 \mathrm{~T}$ Siemens Symphony scanner (Siemens Medical Solutions Diagnostics). Coefficients of variation for all the following methodologies have been previously published $(21,27,28)$, and the methodologies are summarised below:

Volumetric analysis of subcutaneous and visceral fat Abdominal subcutaneous adipose tissue (SAT) and abdominal visceral adipose tissue (VAT) was calculated from whole-body axial $\mathrm{T}_{1}$-weighted fast spin echo scans (axial scans, $10 \mathrm{~mm}$ slice thickness followed by a $10 \mathrm{~mm}$ gap using the integral body coil). The abdominal region was defined as the image slices from the slice containing the femoral heads, to the slice containing the top of the liver/base of the lungs. All scans were analysed centrally. Scans were anonymised prior to analysis thus ensuring that the observer was blinded to all clinical details.

Proton magnetic resonance spectroscopy In liver, NAFLD was defined as IHCL $>5.6 \%$ (29). Three voxels of interest were identified in the liver standard sites avoiding ducts and vasculature. In skeletal muscle a single voxel was identified in each of the tibialis anterior (TA) and soleus (Sol) muscles, avoiding bone, fascia and the neurovascular bundle. Single voxel spectroscopy was conducted at each of these five sites. Voxel size was $20 \times 20 \times 20 \mathrm{~mm}$, TE $135 \mathrm{~ms}$, TR $1500 \mathrm{~ms}$, with 64 acquisitions. Where the musculature was too small to allow placement of a $20 \mathrm{~mm}$ voxel, a $15 \times 15 \times 20 \mathrm{~mm}$ voxel was placed and the number of acquisitions was increased to 200 to maintain signal-to-noise ratio. In both liver and muscle, voxel placement in posttreatment studies was guided by reference to the pretreatment images. ${ }^{1} \mathrm{H}-\mathrm{MR}$ spectra were quantified using the AMARES algorithm in the software package jMRUI$3.0(30,31)$. As previously described, IHCL is expressed as percent of $\mathrm{CH}_{2}$ lipid signal amplitude relative to water signal amplitude (31) after correcting for $\mathrm{T}_{1}$ and $\mathrm{T}_{2}$ (21), and IMCL is expressed as $\mathrm{CH}_{2}$ lipid amplitude relative to total creatine amplitude after correcting for $\mathrm{T}_{1}$ and $\mathrm{T}_{2}(22)$.

\section{GH replacement}

Individuals who were biochemically GH deficient, and who had impaired quality of life defined as a QOL AGHDA score $\geq 11$ points ('symptomatic' patients), were commenced on GH replacement (GHR) in accordance with UK National Institute of Health and Clinical Excellence (NICE) guidance. The initial GH dose was $0.2 \mathrm{mg} /$ day titrated at monthly intervals to achieve an IGF1 level within the normal range. Patients were supervised by an experienced endocrine nurse and symptoms and signs carefully monitored. Patients with biochemical GHD but with a QOL AGHDA score $<11$ did not commence GH. These patients were studied only once.

\section{Statistical analysis}

As this was an exploratory study, no power calculation was undertaken. By the same rationale, no correction for multiple comparisons has been undertaken and as such results should be considered as hypothesis generating rather than conclusive. Normally distributed variables are presented as mean and s.D. and nonnormally distributed variables as median and interquartile range. Categorical variables are presented as counts. Where the relevant assumptions were met, the independent samples $t$-test was used to compare the healthy control and GHD groups on continuous demographic variables. Where natural log transformation was unsuccessful in achieving normality, the Mann-Whitney $U$ test was used. For categorical variables the $\chi^{2}$ test was used to compare the healthy control and GHD groups. ANCOVA was used to compare IHCL between the healthy control and GHD groups in order to correct for potentially confounding differences between groups, despite mean matching.

For those patients measured before and after GHR, paired $t$-tests were used to determine the size of the difference between time points, where the relevant assumptions were met. Otherwise the Wilcoxon matched pairs test was used. For all parametric statistical tests undertaken, an estimate of the difference between groups with corresponding confidence interval 
is provided. Where variables have been log transformed this 'difference' represents the ratio of geometric means. Correlation analyses were performed using Spearman's non-parametric rank correlation coefficient. Calculations were performed using Stata Statistical Software (Stata Statistical Software: release 12; StataCorp LP, College Station, TX, USA) and GraphPad Prism (version 5.0 for Windows; GraphPad Software, San Diego, CA, USA). $P<0.05$ (two-tailed) was considered statistically significant.

\section{Results}

When comparing GHD patients and controls, differences in age, BMI, gender and waist circumference were sufficiently small to be able to consider them comparable (see Table 2). As expected, IGF1 was significantly lower in GHD; however, no differences were noted in ALT, AST, GGT or plasma lipid measurements. Alcohol intake was greater in the control group (median: 11 units, controls vs 3 units, patients, $P=0.01$ ); however, there was no association between alcohol intake and liver fat in this group $(r=0.24$, $P=0.27$ ). There were no differences between symptomatic GHD (SGHD) patients and asymptomatic GHD (AGHD) patients in any measurements, including IGF1 (SGHD $12(0-29) \mathrm{nmol} / \mathrm{l}$ vs AGHD $11(7-36) \mathrm{nmol} / \mathrm{l}$; $P=0.77)$ and peak GH (SGHD $1.53(0-3.0) \mu \mathrm{g} / \mathrm{l}$ vs AGHD 1.09 (0-2.33); $P=0.82$ ). All patients with GHD were therefore analysed as a single group. There was no correlation between severity of GHD (as measured by number of associated pituitary hormone defects) and the level of IHCL, IMCL or SAT. There was a positive association between the number of associated pituitary hormone defects and quantity of VAT $(r=0.4, P=0.03)$.

\section{Abdominal VAT and abdominal SAT}

VAT was significantly greater in GHD than in controls, despite there being no significant difference in SAT. There was a correlation between VAT and IHCL and IMCL-TA but not IMCL-Sol in controls (Table 3), while in GHD only IMCL-TA was correlated with VAT.

\section{Intrahepatocellular lipid}

IHCL was correlated with BMI in both the patient and control groups (Fig. 1). ANCOVA was used to compare liver fat between the two groups while correcting for BMI in order to robustly correct for small differences between the groups. In this analysis the ratio of geometric means was $0.81(95 \%$ CI: $0.38,1.72)$, $P=0.72$ indicating that it was not possible to demonstrate a difference between the two groups even after correction for BMI. There was no significant difference in the proportion of patients with IHCL $>5.6 \%$ in each group (GHD 32\%, controls 50\%, difference $19 \%$ (95\% CI: $45 \%, 7 \%) P=0.16)$, and no significant difference in IHCL after adjustment for the covariates of age, gender and BMI $(P=0.35)$. There was no correlation between IHCL and age or gender in either group. IHCL was negatively correlated

Table 2 Baseline characteristics of control subjects and GHD patients. Results presented as median and range.

\begin{tabular}{|c|c|c|c|c|}
\hline Measurement & Controls $(n=24)$ & GHD $(n=28)$ & Difference $(95 \% \mathrm{Cl})$ & $P$ value \\
\hline Age (years) & $52.6(12.0)$ & $52.6(14.0)$ & $-0.1(-7.5$ to 7.4$)$ & 0.99 \\
\hline $\mathrm{BMI}\left(\mathrm{kg} / \mathrm{m}^{2}\right)$ & $27.9(25.1,32.1)$ & $27.8(24.7,34.7)$ & - & 0.93 \\
\hline Male:female & $16: 8$ & $20: 8$ & - & 0.71 \\
\hline Waist circumference $(\mathrm{cm})^{a}$ & $101(94,112)$ & $101(93,115)$ & 0.99 (0.92 to 1.06$)$ & 0.70 \\
\hline Hip circumference $(\mathrm{cm})^{\mathrm{a}}$ & $105(100,114)$ & $101(97,117)$ & $1.0(0.95$ to 1.08$)$ & 0.61 \\
\hline AGHDA & - & $14(5.5,19.5)$ & - & - \\
\hline Peak GH $(\mu \mathrm{g} / \mathrm{l})$ & - & $1.1(0.2,2.3)$ & - & - \\
\hline IGF1 (nmol//) & $18.0(14.0,23.0)$ & $11.5(9.0,16.5)$ & - & 0.0007 \\
\hline Random GH $(\mu \mathrm{g} / \mathrm{l})$ & $0.11(0.06,0.26)$ & $0.15(0.06,0.40)$ & - & 0.68 \\
\hline Fasting glucose $(\mathrm{mmol} / \mathrm{l})$ & $5.0(0.6)$ & $4.8(0.7)$ & $0.2(-0.2$ to 0.5$)$ & 0.41 \\
\hline $\operatorname{ALT}(\mu / l)$ & $26.0(24.0,35.0)$ & $24.5(20.0,31.5)$ & - & 0.35 \\
\hline $\operatorname{AST}(\mu / /)^{a}$ & $27.5(21.5,31.5)$ & $25.0(21.0,35.0)$ & $1.06(0.85$ to 1.31$)$ & 0.61 \\
\hline $\operatorname{GGT}(\mu / I)^{a}$ & $32(24,45)$ & $25(18,56)$ & $1.05(0.74$ to 1.52$)$ & 0.75 \\
\hline Cholesterol (mmol/l) & $5.6(4.6,6.0)$ & $5.0(4.7,5.6)$ & - & 0.38 \\
\hline $\mathrm{HDL}(\mathrm{mmol} / \mathrm{l})$ & $1.3(1.2,1.6)$ & $1.2(1.1,1.4)$ & - & 0.05 \\
\hline $\mathrm{LDL}(\mathrm{mmol} / \mathrm{l})$ & $3.4(2.9,4.0)$ & $3.0(2.7,3.5)$ & - & 0.19 \\
\hline TGs (mmol/l) & $1.2(1.1,1.4)$ & $1.4(1.1,1.9)$ & - & 0.11 \\
\hline $\mathrm{IHCL}\left(\% \mathrm{CH}_{2} / \text { water }\right)^{\mathrm{a}}$ & $5.0(1.5,12.7)$ & $2.8(1.3,8.6)$ & $1.17(0.49$ to 2.78$)$ & 0.72 \\
\hline IMCL-Sol $\left(\mathrm{CH}_{2} /\right.$ creatine $^{\mathrm{a}}$ & $11.5(6.6,15.8)$ & $12.3(6.4,18.4)$ & $0.97(0.70$ to 1.36$)$ & 0.87 \\
\hline IMCL-TA $\left(\mathrm{CH}_{2} / \text { creatine }\right)^{\mathrm{a}}$ & $6.9(5.3,15.0)$ & $6.9(2.0,32.7)$ & 0.78 (0.50 to 1.22$)$ & 0.27 \\
\hline Abdominal SAT (I) & $5.8(4.3,7.4)$ & $5.7(4.6,11.8)$ & - & 0.78 \\
\hline Abdominal VAT $\left(\mathrm{I}^{\mathrm{a}}\right.$ & $3.6(3.0,5.8)$ & $5.8(4.3,7.4)$ & 0.75 (0.57 to 0.99$)$ & 0.04 \\
\hline
\end{tabular}

aVariables analysed after logarithmic transformation. 
Table 3 Association of clinical, biochemical and magnetic resonance imaging parameters with intrahepatocellular lipid (IHCL), intramyocellular lipid (IMCL)-soleus (Sol) and IMCL-tibialis anterior (TA) in 28 patients with GHD and 24 controls.

\begin{tabular}{|c|c|c|c|c|c|c|c|c|c|}
\hline & \multicolumn{3}{|c|}{ IHCL } & \multicolumn{3}{|c|}{ IMCL-TA } & \multicolumn{3}{|c|}{ IMCL-Sol } \\
\hline & $n$ & $r$ & $P$ & $n$ & $r$ & $P$ & $n$ & $r$ & $P$ \\
\hline \multicolumn{10}{|l|}{ Controls } \\
\hline \multicolumn{10}{|l|}{ Clinical } \\
\hline Age (years) & 24 & 0.119 & 0.607 & 23 & 0.531 & $0.009^{\star}$ & 23 & 0.590 & $0.003^{\star}$ \\
\hline Gender & 24 & 0.139 & 0.5 & 23 & -0.05 & 0.829 & 23 & -0.032 & 0.886 \\
\hline BMI $\left(\mathrm{kg} / \mathrm{m}^{2}\right)$ & 24 & 0.608 & $0.003^{*}$ & 23 & 0.356 & 0.1 & 23 & 0.176 & 0.422 \\
\hline Waist circumference $(\mathrm{cm})$ & 24 & 0.464 & $0.03^{\star}$ & 23 & 0.445 & $0.03^{*}$ & 23 & 0.241 & 0.268 \\
\hline \multicolumn{10}{|l|}{ Biochemical } \\
\hline $\operatorname{ALT}(\mu / l)$ & 22 & 0.455 & $0.05^{\star}$ & 21 & 0.026 & 0.911 & 21 & 0.006 & 0.980 \\
\hline AST $(\mu / \mathrm{l})$ & 24 & -0.31 & 0.884 & 23 & -0.099 & 0.652 & 23 & -0.03 & 0.884 \\
\hline GGT $(\mu / l)$ & 22 & 0.533 & $0.015^{\star}$ & 21 & -0.183 & 0.428 & 21 & 0.294 & 0.196 \\
\hline Fasting glucose $(\mathrm{mmol} / \mathrm{l})$ & 24 & 0.237 & 0.302 & 23 & 0.101 & 0.647 & 24 & 0.002 & 0.991 \\
\hline Total cholesterol $(\mathrm{mmol} / \mathrm{l})$ & 23 & 0.3 & 0.199 & 22 & -0.118 & 0.6 & 22 & -0.144 & 0.522 \\
\hline Fasting TG $(\mathrm{mmol} / \mathrm{l})$ & 23 & 0.304 & 0.2 & 22 & -0.039 & 0.862 & 23 & -0.025 & 0.912 \\
\hline $\mathrm{HDL}(\mathrm{mmol} / \mathrm{l})$ & 23 & 0.287 & 0.2 & 22 & 0.088 & 0.7 & 23 & 0.003 & 0.990 \\
\hline $\mathrm{LDL}(\mathrm{mmol} / \mathrm{l})$ & 23 & 0.122 & 0.6 & 21 & -0.110 & 0.627 & 23 & -0.172 & 0.444 \\
\hline IGF1 (nmol/I) & 23 & -0.504 & $0.02^{\star}$ & 22 & -0.259 & 0.244 & 22 & -0.260 & 0.243 \\
\hline \multicolumn{10}{|l|}{ Body composition } \\
\hline Abdominal SAT (I) & 22 & 0.216 & 0.4 & 22 & 0.06 & 0.793 & 22 & -0.04 & 0.859 \\
\hline Abdominal VAT (I) & 22 & 0.677 & $0.001^{*}$ & 22 & 0.580 & $0.005^{\star}$ & 22 & 0.300 & 0.175 \\
\hline \multicolumn{10}{|l|}{ GHD } \\
\hline \multicolumn{10}{|l|}{ Clinical } \\
\hline Age (years) & 28 & -0.12 & 0.52 & 27 & 0.119 & 0.555 & 27 & 0.680 & $<0.001^{\star}$ \\
\hline Gender & 28 & 0.03 & 0.88 & 27 & 0.062 & 0.757 & 27 & -0.187 & 0.349 \\
\hline BMl $\left(\mathrm{kg} / \mathrm{m}^{2}\right)$ & 28 & 0.48 & $0.01^{\star}$ & 27 & 0.216 & 0.279 & 27 & -0.332 & 0.09 \\
\hline Waist circumference $(\mathrm{cm})$ & 27 & 0.46 & $0.02^{*}$ & 26 & 0.305 & 0.130 & 26 & -0.163 & 0.425 \\
\hline \multicolumn{10}{|l|}{ Biochemical } \\
\hline $\operatorname{ALT}(\mu / l)$ & 28 & 0.52 & $0.004^{\star}$ & 27 & 0.000 & 0.999 & 27 & 0.1 & 0.625 \\
\hline AST $(\mu / l)$ & 22 & 0.21 & 0.34 & 21 & -0.104 & 0.655 & 21 & 0.073 & 0.753 \\
\hline GGT $(\mu / L)$ & 23 & 0.45 & $0.03^{\star}$ & 22 & -0.018 & 0.936 & 22 & -0.019 & 0.932 \\
\hline Fasting glucose $(\mathrm{mmol} / \mathrm{l})$ & 27 & 0.5 & $0.008^{*}$ & 26 & 0.453 & $0.02^{\star}$ & 26 & 0.108 & 0.599 \\
\hline Total cholesterol $(\mathrm{mmol} / \mathrm{l})$ & 28 & -0.22 & 0.24 & 27 & 0.399 & 0.169 & 27 & 0.119 & 0.555 \\
\hline Fasting TG (mmol//) & 25 & 0.06 & 0.78 & 24 & -0.150 & 0.485 & 24 & -0.068 & 0.751 \\
\hline $\mathrm{HDL}(\mathrm{mmol} / \mathrm{l})$ & 28 & 0.05 & 0.78 & 27 & -0.274 & 0.167 & 27 & -0.096 & 0.633 \\
\hline $\mathrm{LDL}(\mathrm{mmol} / \mathrm{l})$ & 23 & -0.08 & 0.97 & 22 & 0.140 & 0.536 & 22 & -0.013 & 0.954 \\
\hline IGF1 (nmol/l) & 28 & -0.26 & 0.18 & 27 & -0.319 & 0.104 & 27 & -0.171 & 0.393 \\
\hline \multicolumn{10}{|l|}{ Body composition } \\
\hline Abdominal SAT (I) & 28 & 0.370 & $0.05^{\star}$ & 25 & 0.301 & 0.127 & 27 & -0.402 & $0.04^{\star}$ \\
\hline Abdominal VAT (I) & 28 & 0.184 & 0.34 & 25 & 0.395 & $0.041^{*}$ & 27 & 0.026 & 0.899 \\
\hline
\end{tabular}

${ }^{*} P$ value $<0.05$

with IGF1 in the control group $(r=-0.50, P=0.02)$ but not the patient group.

\section{Intramyocellular lipid}

There was no significant difference between the groups in IMCL in either TA or Sol muscles $(P=0.3(\mathrm{TA})$; $P=0.9$ (Sol)). IMCL increased with age with the exception of IMCL-TA in GHD. IMCL-TA was positively correlated with VAT in both groups, but not with BMI. There was no association between IMCL and IHCL in either group.

\section{Hepatic enzymes}

IHCL was associated with ALT and GGT in both controls and patients (Table 3). In addition, ALT was positively correlated with VAT in patients but not controls, and GGT was inversely associated with IGF1 in both groups (controls: $r=-0.65, P=0.001$; GHD: $r=-0.65$, $P=0.001)$.

\section{Lipid profiles and fasting glucose}

There was no significant difference between total cholesterol, HDL or LDL between the groups. No components of the lipid profile had any significant association with IHCL in either group; however, fasting TG was negatively correlated with IGF1 in GHD. There was no difference in fasting glucose between patients and controls, although there was a positive correlation with age in both groups (controls: $r=0.46$, $P=0.02$; GHD: $r=0.46, P=0.02$ ). While there was no association between IHCL and fasting glucose in controls, there was a positive correlation in GHD (see Table 3). 

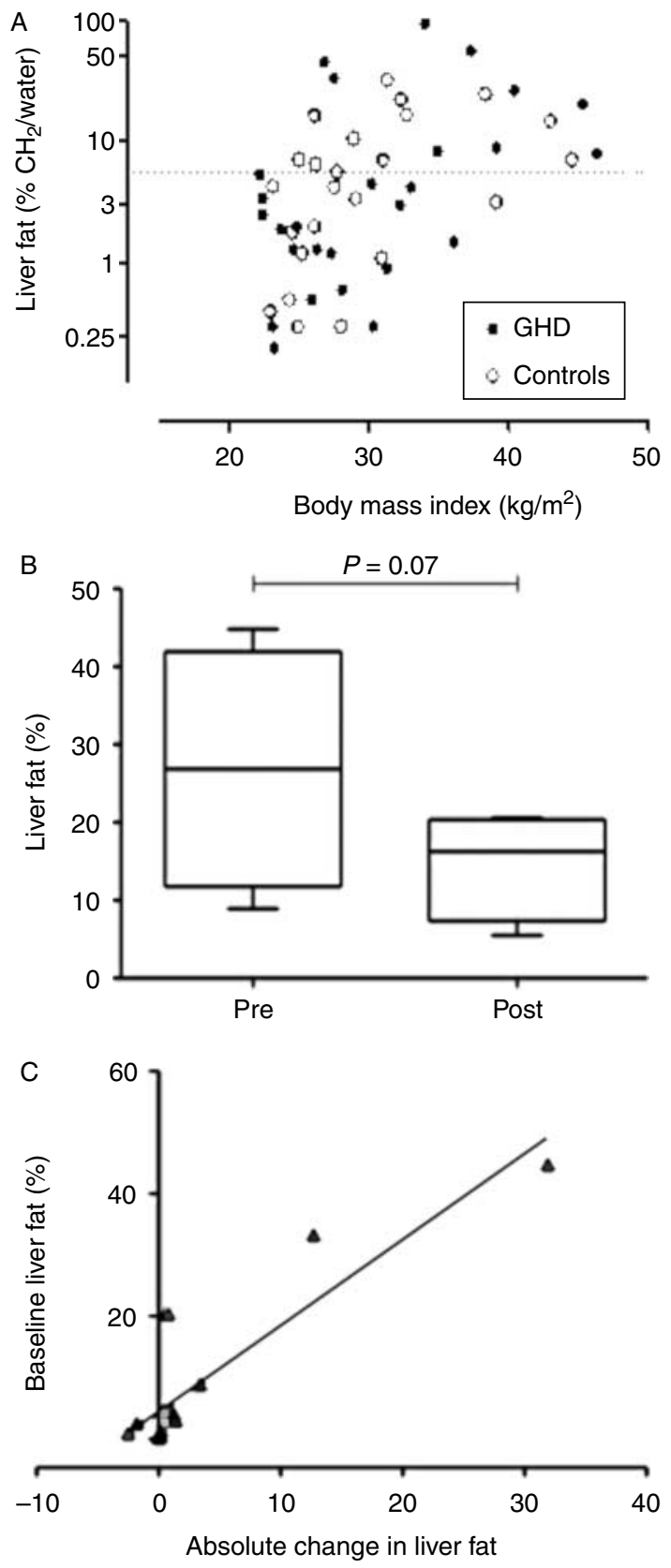

Figure 1 (A) Relationship between liver fat (logarithmically transformed) and BMI in GHD patients and healthy controls, demonstrating no difference in liver fat between patients and controls; dashed line indicates liver fat of $5.6 \%$ (definition of NAFLD on MRS). (B) Box and whisker plot demonstrating reduction in liver fat following 6 months of $\mathrm{rGH}$ in four patients with elevated liver fat at baseline. (C) Scatterplot demonstrating the correlation between baseline liver fat and absolute change in liver fat $(r=0.906$; $P \leq 0.001)$.

\section{Insulin-like growth factor 1}

In controls IGF1 was associated with all markers of adiposity (waist circumference, BMI, VAT and SAT, the correlation being most striking for VAT $(r=-0.615$,
$P=0.035)$. IGF1 was inversely correlated with IHCL in controls, even after correction for age and VAT $(r=-0.504, P=0.028)$. In GHD there was no association between IHCL and IGF1 levels, or with markers of adiposity (BMI, waist circumference, VAT or SAT).

\section{Effect of rGH}

Results are summarised in Table 4 and Fig. 1. Twelve patients completed 6 months of rGH treatment, of whom four had NAFLD (liver fat $>5.6 \%$ ). Both VAT and SAT reduced in response to treatment, with the VAT:SAT ratio also reducing significantly $(P=0.02)$, indicating a proportionately greater reduction in visceral fat. There was no overall change in IHCL (preGH, 2.7\% (0.2-44.8\%); post-GH, 3.2\% (0.1-20.6\%); $P=0.1)$. However, after subdividing the patient group into those with high $(n=4)$ and low $(n=8)$ baseline liver fat (defined as $>5.6 \%$ or $<5.6 \%$ liver fat), reductions in liver fat were seen in the high liver fat group treated with rGH (Fig. 1b); however, this was not statistically significant $(P=0.07)$. The magnitude of change in IHCL was positively correlated with the baseline IHCL $(r=0.906, P \leq 0.001)$, thus patients with the highest higher initial liver fat demonstrated the greatest improvement (Fig. 1c).

\section{Discussion}

This study reveals several interesting and novel observations. First, despite higher VAT in GHD patients compared with age, gender and BMI-matched controls, there was no difference in the liver or skeletal muscle fat content between the two groups, neither was there any difference in the proportion of people with hepatic steatosis in either group. This finding does not support previous observations of an increased prevalence of NAFLD in patients with GHD. Second, these data provide an important insight into regulation of fat deposition by $\mathrm{GH}$ with a differential effect of $\mathrm{GH}$ on the various fat depots. Clearly, the most significant effect was the reduction by $\mathrm{GH}$ treatment on visceral (vs subcutaneous) fat. While GHD patients with hepatic steatosis experienced a reduction in liver fat content following treatment with $\mathrm{rGH}$, this did not attain statistical significance $(P=0.07)$.

We deliberately included a range of BMI and ages to make our study group representative of patients with GHD encountered in practice. The BMI of our patients at $27.8 \mathrm{~kg} / \mathrm{m}^{2}$ was similar to the range of BMI $\left(28.5-29.9 \mathrm{~kg} / \mathrm{m}^{2}\right)$ seen in the GHD patients in a recent analysis of the KIMS database (Pfizer International Metabolic Database) (11). Furthermore, our study group reflects a range of pituitary pathologies, which is a good representation of the average clinic population. We therefore believe that we have obtained a representative sample of the GHD population. 
Table 4 Anthropometric, biochemical and magnetic resonance imaging-derived parameters pre- and 6 months post-GH replacement in 12 patients (five females) with GHD. Results presented as median and range.

\begin{tabular}{|c|c|c|c|c|}
\hline Parameter & Pre-GH & Post-GH & Effect size $(95 \% \mathrm{Cl})$ & $P$ value \\
\hline Weight & $75.4(69.5,96.4)$ & $77.7(69.4,98.4)$ & $0.4(-1.9$ to 1.1$)$ & 0.58 \\
\hline BMI $\left(\mathrm{kg} / \mathrm{m}^{2}\right)$ & $28.9(24.6,33.0)$ & $30.0(25.6,33.2)$ & $0.2(-0.4$ to 0.8$)$ & 0.54 \\
\hline IGF1 (nmol/l) & $12(9,12)$ & $25(21,29)$ & $13(9$ to 17$)$ & $<0.00005$ \\
\hline $\operatorname{ALT}(\mu / \mathrm{l})$ & $21(17,34)$ & $28(14,32)$ & $1(-13$ to 15$)$ & 0.88 \\
\hline AST $(\mu / l)$ & $24(22,37)$ & $23(20,26)$ & $2(-12$ to 16$)$ & 0.75 \\
\hline GGT $(\mu / l)$ & $29(20,56)$ & $33(20,45)$ & - & 0.06 \\
\hline Cholesterol (mmol/l) & $5.3(4.7,5.7)$ & $5.0(4.7,5.6)$ & $-0.2(-0.6$ to 0.2$)$ & 0.26 \\
\hline $\mathrm{LDL}(\mathrm{mmol} / \mathrm{l})$ & $3.3(2.6,4.4)$ & $3.1(2.7,3.8)$ & $-0.2(-0.9$ to 0.6$)$ & 0.65 \\
\hline $\mathrm{HDL}(\mathrm{mmol} / \mathrm{l})$ & $1.15(1.0,1.4)$ & $1.3(0.9,1.4)$ & - & 0.65 \\
\hline $\mathrm{TG}(\mathrm{mmol} / \mathrm{l})$ & $1.6(1.4,1.9)$ & $1.6(1.3,2.5)$ & - & 0.80 \\
\hline Glucose (mmol/l) & $4.8(4.4,5.3)$ & $5.0(4.5,5.4)$ & $0.24(-0.06$ to 0.53$)$ & 0.10 \\
\hline IHCL (\% $\mathrm{CH}_{2} /$ water) & $2.8(0.6,14.7)$ & $3.2(0.8,9.2)$ & - & 0.10 \\
\hline IMCL-TA $\left(\mathrm{CH}_{2} /\right.$ creatinine $)$ & $7.0(6.2,9.5)$ & $7.4(6.9,11.5)$ & $1.0(-2.4$ to 4.6$)$ & 0.51 \\
\hline IMCL-Sol ( $\mathrm{CH}_{2} /$ creatinine $)$ & $10.2(6.0,16.6)$ & $12.3(8.9,16.1)$ & $0.9(-3.2$ to 5.1$)$ & 0.63 \\
\hline Abdominal VAT (I) & $5.6(4.2,6.7)$ & $4.4(3.2,5.1)$ & $-1.5(-2.3,-0.62)$ & 0.0027 \\
\hline Abdominal SAT (I) & $6.2(4.3,11.9)$ & $6.8(3.8,11.2)$ & $-0.6(-0.9$ to -0.2$)$ & 0.0026 \\
\hline VAT:SAT ratio & $0.8(0.6,1.3)$ & $0.71(0.4,1.0)$ & - & 0.02 \\
\hline
\end{tabular}

Despite the reductions seen in IGF1 with obesity, our GHD patients had significantly lower IGF1 levels than our control group, reflecting the pituitary rather than hepatic origin of the IGF1 deficiency in this group.

By using ${ }^{1} \mathrm{H}-\mathrm{MRS}$ rather than modalities such as CT (measuring liver to spleen attenuation ratio) or ultrasonography, which are able to assess steatosis semi-quantitatively (32), we were able to quantify steatosis very precisely. Many previous studies used liver transaminases as a surrogate marker of NAFLD; these may be normal in up to $80 \%$ of cases (33). In contrast, we can be certain of identifying all cases of NAFLD within both of our study groups. The elevated VAT in this population is consistent with the previously reported phenotype of patients with GHD, having a higher ratio of visceral to subcutaneous fat compared with controls matched for BMI. Furthermore, in those patients given GHR, improvements in body composition were seen with significant reductions in both subcutaneous and visceral fat in keeping with recent data from Eggar et al. (34) and the recent meta-analysis by Hazem et al. (35). Our primary outcome measure was IHCL. Our finding that hepatic steatosis is equally common in our cohort of patients with GHD and controls is in contrast to a number of previous studies, all of which have significant limitations. Ichikawa et al. (2) found an increased incidence of NAFLD (7/13 vs 0/5) in 18 lean patients with hypopituitarism, but with and without GHD. The two groups had similar BMI, but neither group of patients was overweight. Furthermore, diagnosis was made by liver to spleen attenuation ratio using CT, a much less sensitive technique than ${ }^{1} \mathrm{H}$-MRS. Adams et al. (1) also examined the link between NAFLD and GHD; however, the retrospective methodology and lack of a control group means that no comment could be made on the relative prevalence of NAFLD. Longitudinal analysis of these patients documented rapid weight gain with deterioration of lipid profiles after diagnosis, with NAFLD subsequently being diagnosed as a median of 3 years after the hypothalamo-pituitary insult. These authors speculated that the cause and severity of NAFLD in GHD might be related to the rapid weight gain after diagnosis which has been shown to be a feature in these patients $(1,11)$ rather than the GHD itself. Nyenwe et al. (36) examined patients with hypopituitarism retrospectively for features of the metabolic syndrome and compared them with controls matched for age, obesity, gender and race. They found greater elevations of serum transaminases in patients with hypopituitarism and untreated GHD, although the overall number of abnormalities was not significantly different in the two groups (elevated AST 37\% GHD vs 34\% controls). Finally, Hong et al. (37) examined 40 men with hypopituitarism with abdominal ultrasonography and compared them with 34 age-matched controls, finding a higher prevalence of NAFLD in hypopituitary patients (32.5\% controls vs $70.6 \%$ patients). However, the hypopituitary patients had a significantly higher BMI than controls.

We demonstrated an inverse association between IGF1 and IHCL in our control group but not in GHD. A similar association was found by Arturi et al. (38), Stavastano et al. (32) and by Bredella et al. (39) in premenopausal women using methodologies similar to our own, although in that study the association was non-significant after correction for age and visceral adiposity, while in our group the association remained after correcting for these variables. They also demonstrated that peak $\mathrm{GH}$ in the combined GH-releasing hormone/arginine stimulation test was inversely associated with IHCL in pre-menopausal obese women without GHD (39). In regression analysis GH was found to be a significant predictor of IHCL after correction for age and visceral adiposity; however, the cross-sectional nature of this study means that causality 
cannot be inferred. Volzke et al. (40) found an inverse association between IGF1 and severity of hepatic steatosis using a four-point scale in a large cohort of 3863 subjects. They likewise were unable to elucidate the cause and effect relationship of IGF1 and liver disease. Ichikawa et al. (41) demonstrated an association between low IGF1 levels and fibrosis in patients with NAFLD, and an association between low GH levels and steatosis in the same cohort. Lonardo et al. (13) demonstrated that low levels of GH were an independent predictor of NAFLD in male patients. Despite a significantly lower IGF1 in our GHD patients, neither incidence of NAFLD nor median IHCL was significantly different. However, it is possible that blunted GH release existed in our control population as a result of their obesity.

We did not find an overall reduction in IHCL following treatment with rGH. In statistical terms this may be due to the lack of a significant change in IHCL in the majority of patients who had normal IHCL, but this masks reductions in steatosis in those individuals with elevated IHCL. Given the responsiveness of liver fat to hormone replacement demonstrated by our group after 6 weeks of treatment (42), it would be anticipated that 6 months would be an appropriate length of time for some changes to be seen. It would thus appear that there is a differential regulation of the different fat depots (visceral, subcutaneous and liver fat depots) by the GH/IGF1 axis with more critical involvement in the regulation of VAT and SAT mass compared with liver fat, which may primarily be regulated by other physiological mechanisms. The reduction in VAT:SAT ratio also suggests a preferential reduction in VAT rather than SAT, independent of BMI suggesting that $\mathrm{GH}$ makes patients more metabolically healthy. The important correlation between baseline liver fat and the reduction in liver fat is worthy of further study to ascertain whether GH may be beneficial in patients with elevated IHCL although to answer this question, larger and appropriately powered randomised-controlled studies involving NAFLD patients, both with and without GHD, will be required.

This study has some weaknesses. The relatively small numbers of patients, particularly in the intervention arm of this pilot study, mean that conclusions cannot be drawn about the effects of rGH on liver fat in NAFLD patients, and that population estimates of prevalence cannot be performed. We did find a marginally higher alcohol intake in our control population; however the absence of any association between liver fat and alcohol intake means that this finding is unlikely to be of clinical significance. All participants drank within the safe recommended limits (20).

We did not perform liver biopsies in our patients meaning that it was not possible to differentiate between simple steatosis and the more severe steatohepatitis. We were also therefore unable to demonstrate potential benefits in terms of incidence of or improvement in non-alcoholic steatohepatitis which has been reported previously (14), or in hepatic fibrosis, which can paradoxically result in lower IHCL, despite severe liver disease. Future studies will need to address this issue, possibly with the inclusion of transient elastography, clinical fibrosis scores or both (43). Finally, we accept that while this study is aimed to be a proof of concept, some exploratory study techniques such as MRS are unlikely to be helpful in many healthcare settings where this is not routinely available.

In conclusion, we have demonstrated that there is no significant difference in the proportion of people with NAFLD in our patients with GHD compared with controls, despite the increased visceral fat volume in patients with GHD. Six months of rGH appears to demonstrate encouraging results in reducing liver fat in NAFLD patients with significant steatosis; however, this reduction is less pronounced when compared with the marked reduction observed in visceral and subcutaneous fat.

\section{Declaration of interest}

The authors declare that there is no conflict of interest that could be perceived as prejudicing the impartiality of the research reported.

\section{Funding}

Drs C J Gardner and D J Cuthbertson were in receipt of an unrestricted educational research grant from Pfizer. Study design, data collection and data analysis were independent of Pfizer.

\section{Author contribution statement}

C J Gardner: conduct of study, drafting and revision of manuscript. A J Irwin, V L Adams: conduct of study. G J Kemp: data analysis and interpretation J D Bell, E L Thomas, D J Cuthbertson: protocol development and revision of manuscript. C Daousi, I A McFarlane, F Joseph, D J Cuthbertson: revision of manuscript and clinical care of patients.

\section{Acknowledgements}

We would like to thank Chris Morgan, Endocrine Specialist Nurse, for contributing to the clinical care of the GHD patients, Dan Lythgoe for his help with statistical analysis and Terry Owen and the Aintree University Hospitals Volunteer Scheme for their assistance in recruiting controls. Methodology for the MR spectroscopy was established with a grant to DC from the European Federation for the Study of Diabetes.

\section{References}

1 Adams LA, Feldstein A, Lindor KD \& Angulo P. Nonalcoholic fatty liver disease among patients with hypothalamic and pituitary dysfunction. Hepatology 200439 909-914. (doi:10.1002/hep. 20140)

2 Ichikawa T, Hamasaki K, Ishikawa H, Ejima E, Eguchi K \& Nakao K. Non-alcoholic steatohepatitis and hepatic steatosis in patients with adult onset growth hormone deficiency. Gut 2003 52 914. (doi:10.1136/gut.52.6.914) 
3 Deepak D, Furlong NJ, Wilding JP \& MacFarlane IA. Cardiovascular disease, hypertension, dyslipidaemia and obesity in patients with hypothalamic-pituitary disease. Postgraduate Medical Journal 200783 277-280. (doi:10.1136/pgmj.2006.052241)

4 Binnerts A, Deurenberg P, Swart GR, Wilson JH \& Lamberts SW. Body composition in growth hormone-deficient adults. American Journal of Clinical Nutrition 199255 918-923.

5 Salomon F, Cuneo RC, Hesp R \& Sonksen PH. The effects of treatment with recombinant human growth hormone on body composition and metabolism in adults with growth hormone deficiency. New England Journal of Medicine 1989321 1797-1803. (doi:10.1056/NEJM198912283212605)

6 Bengtsson BA, Abs R, Bennmarker H, Monson JP, FeldtRasmussen U, Hernberg-Stahl E, Westberg B, Wilton P \& Wuster $\mathrm{C}$. The effects of treatment and the individual responsiveness to growth hormone $(\mathrm{GH})$ replacement therapy in 665 GH-deficient adults. KIMS Study Group and the KIMS International Board. Journal of Clinical Endocrinology and Metabolism 199984 3929-3935. (doi:10.1210/jc.84.11.3929)

7 Attanasio AF, Bates PC, Ho KK, Webb SM, Ross RJ, Strasburger CJ, Bouillon R, Crowe B, Selander K, Valle D \& Lamberts SW Human growth hormone replacement in adult hypopituitary patients: long-term effects on body composition and lipid status 3-year results from the HypoCCS Database. Journal of Clinica Endocrinology and Metabolism 200287 1600-1606. (doi:10. $1210 /$ jc.87.4.1600)

8 Christ ER, Cummings MH \& Russell-Jones DL. Dyslipidaemia in adult growth hormone $(\mathrm{GH})$ deficiency and the effect of GH replacement therapy: a review. Trends in Endocrinology and Metabolism 19989 200-206. (doi:10.1016/S1043-2760(98) 00050-2)

9 Verhelst J, Kendall-Taylor P, Erfurth EM, Price DA, Geffner M, Koltowska-Haggstrom M, Jonsson PJ, Wilton P \& Abs R. Baseline characteristics and response to 2 years of growth hormone $(\mathrm{GH})$ replacement of hypopituitary patients with $\mathrm{GH}$ deficiency due to adult-onset craniopharyngioma in comparison with patients with nonfunctioning pituitary adenoma: data from KIMS (Pfizer International Metabolic Database). Journal of Clinical Endocrinology and Metabolism 200590 4636-4643. (doi:10.1210/jc.20050185)

10 Marchesini G, Brizi M, Bianchi G, Tomassetti S, Bugianesi E, Lenzi M, McCullough AJ, Natale S, Forlani G \& Melchionda N. Nonalcoholic fatty liver disease: a feature of the metabolic syndrome. Diabetes $2001501844-1850$. (doi:10.2337/diabetes. 50.8.1844)

11 van Beek AP, Wolffenbuttel BH, Runge E, Trainer PJ, Jonsson PJ \& Koltowska-Haggstrom M. The pituitary gland and age-dependent regulation of body composition. Journal of Clinical Endocrinology and Metabolism 201095 3664-3674. (doi:10.1210/jc.20092506)

12 Rosen T, Eden S, Larson G, Wilhelmsen L \& Bengtsson BA. Cardiovascular risk factors in adult patients with growth hormone deficiency. Acta Endocrinologica 1993129 195-200.

13 Lonardo A, Loria P, Leonardi F, Ganazzi D \& Carulli N. Growth hormone plasma levels in nonalcoholic fatty liver disease. American Journal of Gastroenterology $2002 \quad \mathbf{9 7}$ 1071-1072. (doi:10.1111/j.1572-0241.2002.05641.x)

14 Tai TS, Lin SY \& Sheu WH. Metabolic effects of growth hormone therapy in an Alstrom syndrome patient. Hormone Research 2003 60 297-301. (doi:10.1159/000074248)

15 Takano S, Kanzaki S, Sato M, Kubo T \& Seino Y. Effect of growth hormone on fatty liver in panhypopituitarism. Archives of Disease in Childhood 199776 537-538. (doi:10.1136/adc.76.6.537)

16 Takahashi Y, Iida K, Takahashi K, Yoshioka S, Fukuoka H, Takeno R, Imanaka M, Nishizawa H, Takahashi M, Seo Y, Hayashi Y, Kondo T, Okimura Y, Kaji H, Kitazawa R, Kitazawa S \& Chihara K. Growth hormone reverses nonalcoholic steatohepatitis in a patient with adult growth hormone deficiency. Gastroenterology 2007132 938-943. (doi:10.1053/j.gastro.2006.12.024)

17 Franco C, Brandberg J, Lonn L, Andersson B, Bengtsson BA \& Johannsson G. Growth hormone treatment reduces abdominal visceral fat in postmenopausal women with abdominal obesity: a 12-month placebo-controlled trial. Journal of Clinical Endocrinology and Metabolism 200590 1466-1474. (doi:10.1210/jc.20041657)

18 Mekala KC \& Tritos NA. Effects of recombinant human growth hormone therapy in obesity in adults: a meta analysis. Journal of Clinical Endocrinology and Metabolism $2009 \quad 94 \quad 130-137$. (doi:10.1210/jc.2008-1357)

19 Pasarica M, Zachwieja JJ, Dejonge L, Redman S \& Smith SR. Effect of growth hormone on body composition and visceral adiposity in middle-aged men with visceral obesity. Journal of Clinical Endocrinology and Metabolism 200792 4265-4270. (doi:10.1210/jc.2007-0786)

20 Anstee QM, McPherson S \& Day CP. How big a problem is non-alcoholic fatty liver disease? BMJ $2011 \quad \mathbf{3 4 3}$ d3897. (doi:10.1136/bmj.d3897)

21 Thomas EL, Hamilton G, Patel N, O'Dwyer R, Dore CJ, Goldin RD, Bell JD \& Taylor-Robinson SD. Hepatic triglyceride content and its relation to body adiposity: a magnetic resonance imaging and proton magnetic resonance spectroscopy study. Gut 2005 54 122-127. (doi:10.1136/gut.2003.036566)

22 Rico-Sanz J, Thomas EL, Jenkinson G, Mierisova S, Iles R \& Bell JD. Diversity in levels of intracellular total creatine and triglycerides in human skeletal muscles observed by (1)H-MRS. Journal of Applied Physiology 199987 2068-2072.

23 Fabbrini E, Magkos F, Mohammed BS, Pietka T, Abumrad NA, Patterson BW, Okunade A \& Klein S. Intrahepatic fat, not visceral fat, is linked with metabolic complications of obesity. PNAS 2009 106 15430-15435. (doi:10.1073/pnas.0904944106)

24 Schrauwen-Hinderling VB, Hesselink MK, Schrauwen P \& Kooi ME. Intramyocellular lipid content in human skeletal muscle. Obesity 200614 357-367. (doi:10.1038/oby.2006.47)

25 McKenna SP, Doward LC, Alonso J, Kohlmann T, Niero M, Prieto L \& Wiren L. The QoL-AGHDA: an instrument for the assessment of quality of life in adults with growth hormone deficiency. Quality of Life Research 19998 373-383. (doi:10.1023/A:1008987922774)

26 Leong KS, Walker AB, Martin I, Wile D, Wilding J \& MacFarlane IA. An audit of 500 subcutaneous glucagon stimulation tests to assess growth hormone and ACTH secretion in patients with hypothalamic-pituitary disease. Clinical Endocrinology $2001 \mathbf{5 4}$ 463-468. (doi:10.1046/j.1365-2265.2001.01169.x)

27 Rico-Sanz J, Hajnal JV, Thomas EL, Mierisova S, Ala-Korpela M \& Bell JD. Intracellular and extracellular skeletal muscle triglyceride metabolism during alternating intensity exercise in humans. Journal of Physiology $1998 \mathbf{5 1 0}$ (Pt 2) 615-622. (doi:10.1111/ j.1469-7793.1998.615bk.x)

28 Thomas EL, Brynes AE, McCarthy J, Goldstone AP, Hajnal JV, Saeed N, Frost G \& Bell JD. Preferential loss of visceral fat following aerobic exercise, measured by magnetic resonance imaging. Lipids 200035 769-776. (doi:10.1007/s11745-000-0584-0)

29 Szczepaniak LS, Nurenberg P, Leonard D, Browning JD, Reingold JS, Grundy S, Hobbs HH \& Dobbins RL. Magnetic resonance spectroscopy to measure hepatic triglyceride content: prevalence of hepatic steatosis in the general population. American Journal of Physiology. Endocrinology and Metabolism $2005 \mathbf{2 8 8}$ E462-E468. (doi:10.1152/ajpendo.00064.2004)

30 Vanhamme L, van den Boogaart A \& Van Huffel S. Improved method for accurate and efficient quantification of MRS data with use of prior knowledge. Journal of Magnetic Resonance 1997 129 35-43. (doi:10.1006/jmre.1997.1244)

31 Naressi A, Couturier C, Devos JM, Janssen M, Mangeat C, de Beer R \& Graveron-Demilly D. Java-based graphical user interface for the MRUI quantitation package. Magma $2001 \quad 12$ 141-152. (doi:10.1007/BF02668096)

32 Savastano S, Di Somma C, Pizza G, De Rosa A, Nedi V, Rossi A, Orio F, Lombardi G, Colao A \& Tarantino G. Liver-spleen axis, insulin-like growth factor-(IGF)-I axis and fat mass in overweight/ obese females. Journal of Translational Medicine 20119136. (doi:10.1186/1479-5876-9-136) 
33 Browning JD, Szczepaniak LS, Dobbins R, Nuremberg P, Horton JD, Cohen JC, Grundy SM \& Hobbs HH. Prevalence of hepatic steatosis in an urban population in the United States: impact of ethnicity. Hepatology 200440 1387-1395. (doi:10.1002/hep.20466)

34 Egger A, Buehler T, Boesch C, Diem P, Stettler C \& Christ ER. The effect of GH replacement therapy on different fat compartments: a whole-body magnetic resonance imaging study. European Journal of Endocrinology 2011164 23-29. (doi:10.1530/EJE-10-0702)

35 Hazem A, Elamin MB, Bancos I, Malaga G, Prutsky G, Domecq JP, Elraiyah TA, Abu Elnour NO, Prevost Y, Almandoz JP, ZeballosPalacios C, Velasquez ER, Erwin PJ, Natt N, Montori VM \& Murad MH. Therapy in endocrine disease: body composition and quality of life in adults treated with GH therapy: a systematic review and meta-analysis. European Journal of Endocrinology 2012 166 13-20. (doi:10.1530/EJE-11-0558)

36 Nyenwe EA, Williamson-Baddorf S, Waters B, Wan JY \& Solomon SS. Nonalcoholic fatty liver disease and metabolic syndrome in hypopituitary patients. American Journal of the Medical Sciences 2009338 190-195. (doi:10.1097/MAJ.0b013e3181a84bde)

37 Hong JW, Kim JY, Kim YE \& Lee EJ. Metabolic parameters and nonalcoholic fatty liver disease in hypopituitary men. Hormone and Metabolic Research 201143 48-54. (doi:10.1055/ s-0030-1265217)

38 Arturi F, Succurro E, Procopio C, Pedace E, Mannino GC, Lugara M, Procopio T, Andreozzi F, Sciacqua A, Hribal ML, Perticone F \& Sesti G. Nonalcoholic fatty liver disease is associated with low circulating levels of insulin-like growth factor-I. Journal of Clinical Endocrinology and Metabolism 201196 E1640-E1644. (doi:10.1210/jc.2011-1227)

39 Bredella MA, Torriani M, Thomas BJ, Ghomi RH, Brick DJ, Gerweck AV \& Miller KK. Peak growth hormone-releasing hormone-arginine-stimulated growth hormone is inversely associated with intramyocellular and intrahepatic lipid content in premenopausal women with obesity. Journal of Clinical Endocrinology and Metabolism 200994 3995-4002. (doi:10. 1210/jc.2009-0438)

40 Volzke H, Nauck M, Rettig R, Dorr M, Higham C, Brabant G \& Wallaschofski H. Association between hepatic steatosis and serum IGF1 and IGFBP-3 levels in a population-based sample. European Journal of Endocrinology 2009161 705-713. (doi:10.1530/EJE09-0374)

41 Ichikawa T, Nakao K, Hamasaki K, Furukawa R, Tsuruta S, Ueda Y, Taura N, Shibata H, Fujimoto M, Toriyama K \& Eguchi K. Role of growth hormone, insulin-like growth factor 1 and insulin-like growth factor-binding protein 3 in development of non-alcoholic fatty liver disease. Hepatology International $2007 \mathbf{1}$ 287-294. (doi:10.1007/s12072-007-9007-4)

42 Gardner C, Richardson P, Wong C, Polavarapu N, Kemp G \& Cuthbertson D. Hypothyroidism in a patient with non-alcoholic fatty liver disease. BMJ $2011 \mathbf{3 4 2}$ c7199. (doi:10.1136/bmj. c7199)

43 Shah AG, Lydecker A, Murray K, Tetri BN, Contos MJ, Sanyal AJ \& Nash Clinical Research Network. Comparison of noninvasive markers of fibrosis in patients with nonalcoholic fatty liver disease. Clinical Gastroenterology and Hepatology 20097 1104-1112. (doi:10.1016/j.cgh.2009.05.033)

Received 1 January 2012

Revised version received 21 February 2012

Accepted 20 March 2012 